\title{
A NOVÍSSIMA CHINA E O SISTEMA INTERNACIONAL
}

\author{
Paulo G. Fagundes Visentini
}

\begin{abstract}
RESUMO
A chegada da China à periferia em desenvolvimento, com uma agenda política e econômica abrangente, inaugura um novo estágio na projeção internacional chinesa e no próprio sistema mundial. Quais são os objetivos dessa Novíssima China em termos de política internacional? Não são poucos os que identificam nas ações chinesas aspirações ambiciosas de dominação mundial, sucedendo os Estados Unidos como liderança do planeta. Em uma manifestação que beira a sinofobia (como outrora o "perigo amarelo"), argumentam que seu desenvolvimento almeja concentrar a riqueza mundial em suas mãos, quebrando com a economia das demais nações. Tomando como base as relações estabelecidas com o continente africano, defendemos a hipótese de que Pequim inaugura uma nova etapa na grande politica internacional e suplanta a fase em que a Nova China lutava para recuperar sua soberania e desenvolvimento, começando a Novíssima China a transformar o próprio sistema mundial. Para tal, argumentamos que a China busca evitar as hegemonias, tanto a dos Estados Unidos como a dela própria, pois nesse último caso, poderia ter a mesma sorte que a Alemanha nas duas guerras mundiais. Não se trata de uma tarefa fácil, pois a China move-se em meio à fluidez diplomática do período posterior à Guerra Fria e ao envelhecimento do capitalismo contemporâneo em seus centros históricos.
\end{abstract}

PALAVRAS-CHAVE: diplomacia chinesa; sistema internacional; relações China-África.

\section{INTRODUÇÃO}

Em 1949, com a proclamação da República Popular da China (RPC), Mao Zedong anunciava o nascimento da Nova China. Ao longo de três tumultuadas décadas, o país logrou reafirmar sua soberania e a ocupar um espaço político relevante como membro permanente do Conselho de Segurança da Organização das Nações Unidas (ONU), em um contexto de normalização das relações com a comunidade internacional. Nas três décadas seguintes, o país lançou um complexo e dinâmico modelo de desenvolvimento que não apenas alterou substancialmente sua realidade interna, como também teve um profundo impacto nas relações econômicas e geopolíticas internacionais.

Nascia a Novíssima China, um Estado cujo modelo político-econômico os grandes especialistas encontram imensa dificuldade em definir. Um país cuja importância internacional pode ser avaliada pela solicitação de parceria econômica feita em Pequim, em 2009, pela Secretária de Estado Hillary Clinton, em um tom que contrastava vivamente com a arrogância da administração George W. Bush. Ao mesmo tempo, a economia e a diplomacia chinesas conseguem estabelecer relações aparentemente sustentáveis com a periferia em desenvolvimen- to, particularmente com a África, em uma perspectiva que ultrapassa a simples esfera comercial ou diplomacia de influência a ela associada.

O que deseja essa Novíssima China, em termos de política internacional? Não são poucos os que identificam nas ações chinesas aspirações ambiciosas de dominação mundial, sucedendo os Estados Unidos da América (EUA) como liderança do planeta. Em uma manifestação que beira a sinofobia (como outrora o "perigo amarelo"), argumentam que seu desenvolvimento almeja concentrar a riqueza mundial em suas mãos, quebrando com a economia das demais nações. Mas o "problema chinês" é como alcançar o desenvolvimento por meio da integração de $22 \%$ da população mundial aos benefícios da modernidade, sem que o sistema internacional entre em colapso. Para que ele transforme-se gradualmente, a China busca evitar as hegemonias, tanto a dos Estados Unidos como a sua própria, pois, nesse último caso, ela poderia ter a mesma sorte que a Alemanha nas duas guerras mundiais. Não se trata de uma tarefa fácil, pois a China move-se em meio à fluidez diplomática do período posterior à Guerra Fria e ao envelhecimento do capitalismo contemporâneo em seus centros históricos. 


\section{A REINSERÇÃO DA CHINA POPULAR NO SISTEMA INTERNACIONAL}

Durante o ciclo colonial, estruturado ao longo de quase cinco séculos de expansão e hegemonia européia, a Ásia conheceu uma situação de dominação direta e indireta, estagnação e mesmo retrocesso nas diversas esferas da vida social. A China imperial, que até o século XVIII fora, em vários campos, a nação mais avançada do mundo, entrou em uma fase de isolamento, estagnação e declínio. Apenas o Japão escapou a essa sorte, tornando-se uma nação imperialista, apoiada em um militarismo extremamente agressivo.

A I Guerra Mundial, a Revolução Soviética, a II Guerra Mundial e a Revolução Chinesa (com as guerras da Coréia e do Vietnã) geraram uma nova realidade geopolítica. O Japão foi reconstruído, industrializado e integrado à esfera de influência americana, o que posteriormente ocorreu com Taiwan e Coréia do Sul (Tigres Asiáticos). Assim, essa Ásia insular e peninsular do Pacífico passou a integrar o espaço capitalista sob ascendência dos Estados Unidos, enquanto a massa continental asiática fazia parte de um espaço socialista e o sul do continente formava um espaço neutralista, apesar da Guerra do Vietnã. Dessa forma, a Guerra Fria implicava a divisão e fragmentação do espaço asiático em regiões isoladas umas das outras, processo que se aprofundou com a ruptura sinosoviética.

No início dos anos 1970, a China e os Estados Unidos reaproximaram-se, em uma aliança antissoviética, a qual permitiu a Pequim ocupar o assento permanente da China no Conselho de Segurança da ONU e normalizar suas relações com a maioria das nações. Era o fim de um longo isolamento diplomático e marginalização imposta. Ao mesmo tempo, encerrava-se o longo ciclo de conflitos internos. Com o término da Revolução Cultural e a aliança com os EUA, o moísmo com ênfase na luta de classes foi deixado de lado. Mao Zedong morreu em 1976 e o grupo reformista ampliou seu poder gradativamente, nele emergindo a liderança de Deng Xiaoping. No final da década o Partido Comunista da China (PCC) introduziu uma série de reformas econômicas, que culminaram com uma abertura externa seletiva e a adoção de novos padrões de desenvolvimento.

Em 1978 o país adotou a política das Quatro Modernizações, que consagra reformas internas como a descoletivização gradual da agricultura, a introdução de uma economia mercantil dentro de uma estrutura socialista, a criação de áreas específicas para a captação de capital e tecnologia estrangeiras e a instalação de empresas transnacionais, destinadas principalmente à exportação. Nas Zonas Econômicas Especiais (ZEEs), geralmente províncias costeiras, introduziu-se legislações próprias para permitir o estabelecimento de determinados mecanismos capitalistas e o assentamento de capitais e empresas estrangeiras.

A nova linha representava uma mudança na estratégia chinesa. Até o início dos anos 1960, a RPC enfatizara os problemas ligados à sua segurança, pois tratava-se de uma revolução ainda não consolidada, com uma economia débil e vivendo uma conjuntura internacional adversa. Foi a época em que a permanência no bloco soviético afigurava-se como necessária para atingir esse objetivo. Do início da década de 1960 à de 1970, a preocupação do PCC voltou-se para a autonomia e independência, pois, apesar dos inúmeros problemas, o país lograra estabilizar-se, e a aliança com Moscou mais entravava do que auxiliava os planos chineses de tornar-se novamente uma potência de âmbito mundial, politicamente respeitada e economicamente desenvolvida.

A ênfase chinesa voltou-se para a modernização do país em quatro áreas: indústria, agricultu$\mathrm{ra}$, tecnologia e forças armadas. O melhor caminho para atingir esses objetivos seria implementar uma política de reformas econômicas internas, abrir o país ao dinamismo da revolução tecnológica que se iniciava, associar-se à revoada dos gansos asiáticos e tirar o máximo de benefícios econômicos e estratégicos de uma aliança com os Estados Unidos, durante uma fase de distensão internacional. Além disso, a normalização com o Japão, ocorrida em 1978, permitia a Pequim desmantelar progressivamente a Pax Americana na Ásia, que mantivera afastados os dois maiores países da região. Washington percebeu a nova conjuntura unicamente a partir de seus objetivos, sem levar em consideração todos os futuros desdobramentos dessa política.

Ainda que marcada por inúmeras dificuldades bastante conhecidas, a RPC não teria de partir do zero, como a Coréia do Sul dos anos 1950, pois possuía uma base industrial e infraestrutura consideráveis, ainda que insuficientemente moderni- 
zada, satisfatórias para iniciar o desenvolvimento. Por outro lado, a manutenção de uma estrutura socialista paralela, bem como de um considerável volume de população vivendo no campo, permitiram ao setor capitalista da economia dispor de uma mão de obra abundante a um custo extremamente baixo. Educação, saúde, habitação, alimentação e transporte público têm um custo baixo na China, permitindo-lhe uma elevada competitividade. Esse é o significado profundo da ambígua expressão "economia socialista de mercado"1. Além da base material e da estabilidade sócio-política construídas pelo regime socialista, a China possuía ainda a possibilidade de utilizar outros trunfos, que haviam favorecido o desenvolvimento de Taiwan, Hong Kong e Cingapura: a diáspora chinesa e seus recursos financeiros.

Ao alterar a ênfase de sua política da luta de classes para as reformas rumo ao mercado, a abertura externa e a aliança com Washington, os comunistas de Pequim não apenas reinseriam o país no concerto das nações, como multiplicavam os sinais de confiança, destinados a atrair os investimentos de seus compatriotas de além-mar, associando-os ao projeto e modernização e oferecendo-lhes bons negócios. Essa estratégia viria a ser coroada de sucesso, mesmo em relação aos arquiinimigos do outro lado do estreito de Formosa. Com a introdução do princípio de "uma nação, dois sistemas", Pequim conseguiu lograr com êxito a reincorporação dos dois últimos enclaves coloniais, Hong Kong e Macau, respectivamente em 1997 e 1999.

O impacto da inserção mundial da China é intenso, não apenas pela acelerada taxa de crescimento, mas pelo peso econômico e populacional do país, bem como por sua dimensão continental. O problema, entretanto, não diz respeito apenas ao peso da China, mas principalmente às características do projeto chinês. Trata-se de uma potência nuclear, com imensa capacidade militar, além do fato de tratar-se de um modelo de desenvolvimento de pretensões autônomas. A República Popular da China, graças à sua capacidade militar de dissuasão, armamento nuclear, indústria armamentista própria, tecnologia aeroespacial e de mísseis, bem como por ser membro Permanente

\footnotetext{
1 Segundo Medeiros (1999), a economia socialista de mercado consiste na descentralização do planejamento e na centralização do mercado.
}

do Conselho de Segurança da ONU (com poder de veto) é o único país em desenvolvimento que se encontra no núcleo do poder mundial.

\section{TIBETE E TIANANMEN 1989, A PRIMEIRA TENTATIVADE CONTENÇÃO}

Essa espetacular performance, entretanto, teve também um outro lado. A descoletivização do campo levou ao aumento da produção, mas gerou crescentes desigualdades sociais e uma parcela de camponeses sem terra, que se tornaram assalariados ou migraram para as grandes cidades. Em um país com quase 700 milhões de camponeses, isso constitui um problema sério. Embora em menor intensidade, esse fenômeno também atingiu as cidades, em um clima político bem mais complexo. Esse fenômeno agravar-se-á significativamente na segunda metade dos anos 1980, com os impactos da Perestroika soviética.

As reformas soviéticas criaram expectativas imensas de uma rápida inserção internacional da União das Repúblicas Socialistas Soviéticas (URSS), mas concretamente levaram o país à beira do caos sócio-econômico e da ruptura política. Era um caminho bem diverso do chinês. Pequim desencadeara suas reformas internas e abertura externa essencialmente no plano econômico, sem estendê-las ao político, ao contrário de Moscou, que as iniciou pelo sistema político, uma década depois. Ora, os reformistas de Deng Xiaoping desencadearam seu processo de mudanças quando a Revolução Científico-Tecnológica (RCT) encontrava-se ainda em sua fase inicial, além de aproveitarem uma conjuntura internacional mais favorável, conservando seu sistema político unipartidário, o que possibilitou estabilidade e controle sobre as reformas. As reformas de Gorbatchov, por outro lado, deram-se sem um plano estratégico claramente definido, sem controle político e, pior ainda, em um momento em que a RCT já dera ao capitalismo uma dianteira inalcançável.

Os efeitos internacionais da Perestroika e a facilidade com que a URSS estava sendo integrada ao sistema mundial em uma posição politicamente subordinada, levaram determinadas forças políticas (dos EUA, de Taiwan e do próprio país) a tentar atrair a China para o mesmo caminho. Não se tratava de mera "conspiração", pois as tensões sociais e as complexidades políticas (ampliação do número de atores políticos, com interesses específicos) que acompanhavam as econo- 
micamente bem sucedidas reformas chinesas eram consideráveis, além dos dirigentes chineses encontrarem-se divididos quanto aos limites e ao ritmo dessas mesmas reformas.

Uma mobilização popular multifacética e contraditória emergia no país, especialmente como movimento contra a corrupção, e o jovem empresariado e os ultra-reformistas do PCC, nucleados em torno do Primeiro-Ministro Zhao Ziyang, procuraram capitalizá-lo em sua luta contra os reformistas moderados como "movimento pela democracia". A concentração popular na Praça da Paz Celestial (Tiananmen), ponto de inflexão desse confronto, ocorria durante as comemorações do Movimento de 4 de maio de 1919 e a visita de Gorbatchov, que deveria encerrar três décadas de divergência, e motivava os reformistas radicais.

A repressão militar ao movimento em junho de 1989 e a conseqüente derrota dos ultra-reformistas, impediu que a China tivesse o mesmo destino da União Soviética: a desagregação do país e o colapso do regime socialista. É, pois, interessante que naquele ano a estratégia ocidental de luta contra o socialismo teve duas conseqüências opostas: a derrota dos comunistas soviéticos, simbolizada pela derrubada do muro de Berlim, e a vitória dos comunistas chineses, sinalizada pela repressão da Praça da Paz Celestial. Analistas da política internacional interpretaram essa contradição argumentando que se tratava de uma vitória definitiva sobre a URSS, enquanto no caso chinês, o próprio desenvolvimento capitalista necessariamente conduziria, em médio prazo, à adoção de um regime político calcado no modelo ocidental de democracia liberal (a tese da contradição entre abertura econômica e fechamento político).

\section{O FIM DA GUERRA FRIA E A NOVA REA- LIDADE GEOPOLÍTICA NA ÁSIA}

O declínio e, finalmente, a desintegração da URSS puseram fim à Guerra Fria e ao sistema bipolar, abrindo uma nova era de incertezas na construção de uma nova ordem mundial, em uma conjuntura marcada pelo acirramento da competição econômico-tecnológica mundial. O fenômeno da globalização passa, cada vez mais, pela regionalização, isto é, pela formação de pólos econômicos apoiados na integração supranacional em escala regional. E a intensidade do processo de globalização provocou, inicialmente, profundos efeitos desestabilizadores, gerando a fragmentação social e nacional, essa última particularmente presente nos países periféricos. É nesse quadro de reordenamento mundial que a Ásia emerge como uma nova fronteira econômica.

Os problemas e perspectivas da Ásia não podem, contudo, ser avaliados unicamente a partir da perspectiva econômica. A segurança regional levanta uma série de interrogações que, provavelmente, condicionarão as possibilidades econômicas posteriores. A ascensão econômica da China, potencializando o incremento e modernização de seu potencial militar e, conseqüentemente, ampliando sua autonomia político-diplomática, passaram a preocupar particularmente os EUA, que buscam reafirmar sua predominância a um custo mais baixo que durante a Guerra Fria.

A região do sudeste asiático é particularmente sensível ao ingresso da China na economia mundial, por seu peso e por anular certas vantagens comparativas da região. A Associação de Nações do Sudeste Asiático (Asean) tem agido com rapidez, estreitando a cooperação política e econômica entre seus membros, para acelerar o desenvolvimento econômico e garantir a segurança da região. Em 1995, o Vietnã, antigo rival, passou a integrar a organização, seguido por Laos, Mianmar e Camboja, abarcando todo o sudeste asiático.

A evolução da Ásia a partir do fim da Guerra Fria e do desaparecimento da URSS foi rápida e profunda, gerando uma nova realidade ainda não devidamente avaliada, pois suas diversas regiões constitutivas, que se encontravam compartimentadas, têm se encaminhado para a fusão em um único cenário estratégico. De fato, o continente asiático esteve, nesse século, submetido a uma série de divisões, cujas formas e abrangência alteraram-se, sem que o problema desaparecesse. A Guerra Fria não fez senão tornar ainda mais herméticas as fronteiras entre as regiões, tais como o anel insular sob controle norteamericano, a massa continental socialista (dividida desde os anos 1960 entre a China e a Sibéria e Ásia central soviéticas), o subcontinente indiano influenciado pelo neutralismo, o sudeste asiático em conflito e em disputa, o que também era o caso de outra região asiática, o Oriente Médio.

Vários "muros" asiáticos ruíram com a desintegração da URSS em fins de 1991. Desde então, a cooperação entre a Rússia e a RPC tem sido crescente nos campos econômico-comercial, 
tecnológico-militar, diplomático e de segurança. Especialmente importante têm sido as vendas de armamento sofisticado e a transferência de tecnologia avançada no campo aeroespacial e nuclear. A queda do "muro sino-soviético", por outro lado, também permitiu a integração progressiva da Sibéria ao dinamismo econômico da ÁsiaPacífico, seja diretamente ao capitalismo oceânico transnacionalizado, seja via cooperação bilateral com o socialismo de mercado chinês.

A normalização política que se seguiu aos acordos de paz do Camboja em 1992, por sua vez, terminou com o isolamento da Indochina em relação ao restante do sudeste asiático. Essa nova dimensão diplomático-estratégica, associada ao dinamismo econômico da região, propiciou o acercamento sino-vietnamita e uma crescente cooperação de Pequim com a Asean. Tanto os interesses econômicos como a criação de um diálogo permanente no campo da segurança têm criado uma situação de crescente cooperação entre a China e o sudeste asiático. Da mesma maneira, apesar das recorrentes situações de tensão calculada na península coreana e seu entorno, a diplomacia chinesa tem encontrado formas de gerar contínuos rearranjos para evitar possíveis rupturas ou a intrusão de problemas estratégicos no nordeste asiático.

Outra região que possuía uma dinâmica própria e uma inserção internacional específica, e que hoje começa a somar-se ao dinamismo da Ásia Oriental, é o subcontinente indiano. A Índia caracterizava-se por uma industrialização substitutiva e autocentrada, e era aliada de Moscou no plano estratégico (vale dizer, anti-chinesa), apesar de sua diplomacia neutralista voltada ao não alinhamento e ao Terceiro Mundo. O colapso da União Soviética, a ascensão econômica da Ásia Oriental e Sudeste, os efeitos da globalização econômica e da RCT, a normalização das relações da China com seus vizinhos e as novas ameaças à segurança indiana, levaram Nova Delhi tanto a promover uma abertura calculada de sua economia, como a buscar um modus vivendi com a China e a mover-se em direção a uma complexa e ambígua aliança com os Estados Unidos.

Quase simultaneamente, o espaço geopolítico asiático ampliava-se ainda mais com o surgimento de novos estados, resultantes do desmembramento da URSS. A antiga Ásia central Soviética, detentora de uma posição estratégica privilegiada e de imensos recursos naturais, como petróleo e gás, inicialmente manteve sua dependência em relação à Rússia, nos quadros da Comunidade de Estados Independentes (CEI). Mas o rápido declínio econômico, militar e diplomático de Moscou levaram o Cazaquistão, Uzbequistão, Tadjiquistão, Quirguistão e o Turcomenistão a buscarem novas alternativas, inclusive porque as potências médias da região, Irã, Turquia, Arábia Saudita, Paquistão, Índia e China, por motivos econômicos, políticas e por determinadas vinculações históricas, étnicas e religiosas, não permaneciam passivas frente ao vácuo de poder criado na região, projetando sua diplomacia em direção a essa área. Assim, além de ampliado, o conjunto asiático tornou-se mais diversificado, com a abertura de uma "nova fronteira" econômica e política.

A independência dos países muçulmanos da antiga Ásia central Soviética, por outro lado, afetou diretamente o Oriente Médio, ampliando seu hinterland e colocando-o em contato direto com a Ásia. Nascia o Grande Oriente Médio. Como foi mencionado, potências médias da região, como Turquia, Irã, Arábia Saudita e Paquistão, lutam por estender sua influência à Ásia Central, sendo o interminável conflito afegão um dos pivôs do novo jogo geopolítico. Além disso, a fronteira impermeável que antigamente separava a URSS do Oriente Médio desapareceu com a formação dos novos estados.

Washington, por sua vez, busca não apenas ter um acesso direto aos recursos econômicos da Ásia Central, como procura evitar que a região torne-se uma espécie de zona de contato entre a Ásia e a Europa. A reabertura da Rota da Seda, antiga ligação terrestre entre a Europa e a Ásia anterior à era das navegações, é bem mais do que um episódio vinculado ao turismo.

Contudo, de momento, o mais importante é que o potencial conflitivo da região e a dimensão de cerco, real ou potencial, que a estratégia norteamericana provoca (sobretudo em relação à China), fazem que a noção de segurança asiática seja ampliada para a Ásia central e, por meio dessa, ao próprio Oriente Médio. Assim, além dessa última região possuir vínculos econômicos com a Ásia, novos problemas têm permitido o estabelecimento de um contato mais sistemático entre os dois cenários, anteriormente distantes. Lentamente, a Ásia política começa a identificar-se com a Ásia 
geográfica e, ainda mais importante, progressivamente esboça-se a noção de Eurásia, analisada adiante.

\section{A EURÁSIA E A ORGANIZAÇÃO DE COO- PERAÇÃO DE SHANGHAI}

A expansão do cenário estratégico asiático para o interior da Eurásia significa a ampliação de recursos naturais e industriais desse, mas, em um quadro de maior diversidade, igualmente o surgimento de novos problemas e conflitos. Isso afeta tanto os países da Ásia quanto os EUA. Se os primeiros conseguem com isso ampliar seu espaço de manobra econômica e diplomática, por outro, a complexidade contida na nova realidade em formação acrescenta dificuldades a uma região que atravessa uma evolução acelerada (com todas suas implicações) e não conta com mecanismos próprios de segurança coletiva. Para os Estados Unidos, uma Ásia maior, comportando maior número de atores políticos e com uma economia que progressivamente entrelaça o próprio continente, significa maiores dificuldades de influência sobre a evolução político-econômica da região.

Existe também outra nova realidade que tem de ser levada em conta quando se analisa o fenômeno asiático. No estudo dos cenários estratégicos dos anos 1990, alguns analistas referem-se à formação de um "Novo Segundo Mundo", nucleado pela RPC. De fato, como lembra o politólogo britânico Halliday (2007), até 1989 viviam em países classificados como socialistas, 1,7 bilhões de pessoas. Após o colapso do bloco soviético, existiam ainda 1,3 bilhões nessa posição. Não se trata, contudo, de considerar-se esse como um simples elemento residual.

Acadêmicos norte-americanos, como Huntington (1997), destacaram que o fim do conflito Leste-Oeste e o enfraquecimento de ideologias universalistas, como o socialismo, tiveram seu lugar ocupado pelo "conflito de civilizações". Assim, o Novo Segundo Mundo atravessa uma $\mathrm{NEP}^{2}$ que, diferentemente da soviética, não se encontra limitada a "um só país", mas inserida na economia mundial, sobre a qual influi de maneira considerável e crescente. Além disso, ele está gestando um paradigma alternativo para a cons-

\footnotetext{
2 A política econômica socialista apoiada no mercado, que vigorou na URSS entre 1921 e 1927.
}

trução de uma Ordem Mundial não hegemônica, com um modelo de desenvolvimento nacional, de segurança e de governabilidade, o que atrai a atenção mundial, em uma época marcada pela instabilidade posterior à Guerra Fria.

Esse Novo Segundo Mundo ${ }^{3}$ mantém uma discreta e sutil cooperação estratégica com o "Velho Segundo Mundo" (reduzido à CEI), como foi visto, e também tem uma relação menos antagônica do que se poderia pensar com os países capitalistas da Ásia. Por um lado, os modelos de desenvolvimento e os regimes políticos dos países asiáticos possuem fortes semelhanças e importantes interesses comuns, sejam eles formalmente capitalistas, sejam socialistas. Esses modelos político-econômicos, "autoritários e estadistas" na perspectiva norte-americana, encontram-se hoje sob a pressão ocidental, desde o campo dos direitos humanos ao dos mecanismos econômicos. A tendência dos países da região, então, é a de afirmar certo discurso e política comuns. Contudo, alguns são extremamente vulneráveis a esse tipo de pressão, por sua dependência diplomática, militar e comercial em relação aos EUA. Assim, a China, embora esquivando-se formalmente de desempenhar tal papel, acaba sendo a principal garantia do chamado "modelo asiático", um dos responsáveis pelo acelerado crescimento econômico da região.

Existe também outro fator de longo prazo que se encontra associado a esse fenômeno. Com a reincorporação de Hong Kong em 1997 e de Macau em 1999, para os asiáticos simboliza o eclipse do ciclo colonial, o que coincide com a ascensão econômica da região. E os dirigentes asiáticos têm perfeita consciência de que sem a China isso não seria possível, o que não significa ignorar a existência de divergências intra-asiáticas. Observado desde a perspectiva da geopolítica clássica da virada do século, não seria absurdo visualizar a afirmação da massa continental, ou Heartland, que passaria a desafiar a Ilha Mundial. Estaria essa economia, cada vez mais da Ásia continental e menos do Oceano Pacífico, em condições de sobrepujar a hegemonia da economia anglo-saxônica centrada nos grandes espaços marítimos planetários?

3 O conceito de "Novo Segundo Mundo" é apresentado no Estudo de Macrocenários, realizado pela Secretaria de Assuntos Estratégicos (SAE) da Presidência da República durante o governo Fernando Henrique Cardoso. 
Um elemento-chave para responder a essa questão será a posição que o Japão vier a adotar. Esse país, tido até recentemente como paradigma do desenvolvimento asiático, encontra-se em estagnação e na encruzilhada de grandes e inadiáveis decisões. Sua economia enfrenta uma prolongada recessão, a população está envelhecida, o consenso social começa a dar sinais de esgotamento e o sistema político organizado em 1955, durante a Guerra Fria, entrou em colapso, e passa por redefinições que, todavia, ainda não estão suficientemente claras. Contudo, o nó da questão encontra-se justamente na política internacional, em relação à qual Tóquio precisa definir-se: como parte da economia Nichibei, ou seja, como a fronteira oriental do império americano, ou como parte da Ásia e sua fronteira ocidental.

A economia nipônica tem se voltado progressivamente para o continente; as questões de segurança regional têm obrigado o país a um maior envolvimento local (como no caso da península coreana) e as pressões norte-americanas para que o Japão enquadre-se ao novo padrão que a potência protetora busca implementar para a economia mundial, levam muitos estadistas e empresários a defender uma maior autonomia para a nação, apoiando-se no continente. Mas, por outro lado, o Japão ainda depende significativamente dos EUA; são tremendamente vulneráveis às pressões diplomático-militares por sua dependência em matéria de segurança, além de encontrarem fortes reservas entre os países do continente, pois as grandes questões herdadas da II Guerra Mundial ainda não estão solucionadas como o foram na Europa.

Em um plano mais geral, a situação da Ásia encontra-se marcada por uma série de contradições. Os países asiáticos, mesmo a China, continuam favoráveis à manutenção da presença militar americana na região, pois ela garante a segurança regional a um custo reduzido e, ainda, no caso de Pequim, justifica um acercamento entre os asiáticos para conter o "hegemonismo" de Washington na área. Trata-se de uma postura defensiva que acaba, em certa medida, por legitimar a China aos olhos de seus vizinhos. Contudo, as nações asiáticas rechaçam as pressões econômicas e as ingerências políticas norte-americanas, tanto em assuntos internos como externos, que constituiriam justamente os temas mais importantes para a Casa Branca, já que seu poder bélico não é utilizado explicitamente.
As ações que os Estados Unidos desenvolvem na região, devido à necessidade de evitar o surgimento de pólos de poder e de desenvolvimento autônomos na Ásia, conduzem esse país a uma série de atitudes que acabam favorecendo uma razoável acomodação das divergências de Pequim com seus vizinhos. Os EUA têm procurado estabelecer um cerco geopolítico à China, como bem o demonstram os acordos de Washington com a Mongólia, além de fomentar o separatismo no Tibete e em Taiwan, com apoio ao discurso independentista, como observou-se nas eleições taiwanesas de 1996.

Os Estados Unidos também parecem dispostos a instrumentalizar política e economicamente a Índia e o Vietnã como parte de sua estratégia de isolamento da China e de contenção de seu desenvolvimento, tirando proveito da rivalidade desses dois países em relação à Pequim. Contudo, Washington parece desconsiderar que tanto Nova Delhi como Hanói definem-se estrategicamente pelos Cinco Princípios da Coexistência Pacífica e pelo ideário de Bandung, como a China. Assim, apesar de divergências concretas, esses três importantes países asiáticos possuem muitas perspectivas e interesses comuns de longo prazo. A evolução de seu inter-relacionamento recente parece apontar nessa direção.

Para muitos analistas está ocorrendo a emergência da Eurásia como região geopolítica e geoeconômica. Dentre os três grandes centros de desenvolvimento do Hemisfério Norte, sempre houve vínculos estreitos por meio dos Oceanos Pacífico e Atlântico, associando a economia da América do Norte com a da Ásia Oriental e da Europa Ocidental, respectivamente. Mas desde a derrocada do sistema colonial, Ásia e Europa têm caminhado separadas, o que agora começa a mudar. A possibilidade de que um triângulo venha realmente a formar-se poderia alterar o equilíbrio internacional.

A Rússia, por sua vez, ainda que tenha se tornado um parceiro qualitativamente inferior à antiga URSS, tem mantido com países-chave da Ásia uma crescente cooperação em campos particularmente sensíveis, como também foi visto anteriormente. Além disso, esse país constitui precisamente o elo terrestre que serviria de base para a constituição de um grande espaço econômico eurasiano. A Rússia, desde que Evgueni Primakov tornou-se Primeiro Ministro, mas especialmente 
desde que Vladimir Putin assumiu a presidência, passou a reorganizar-se, a crescer economicamente, a recuperar parcialmente sua capacidade militar e a desenvolver um significativo protagonismo diplomático. Além da parceria estratégica estabelecida com a China, ambos os países criaram a Organização de Cooperação de Shanghai, um acordo de caráter econômico e de segurança, que engloba igualmente o Cazaquistão, o Uzbequistão, o Tadjiquistão e o Quirguistão, além de associados e observadores. A Ásia central possui recursos em gás e petróleo que são indispensáveis ao desenvolvimento chinês.

Por fim, importantes países asiáticos individualmente e organizações regionais como AsiaPacific Economic Cooperation (APEC), The Pacific Economic Cooperation Council (PECC), South Asian Association for Regional Cooperation (Saarc) e Asean, entre outras, têm buscado um maior acercamento com países-chave do Terceiro Mundo, particularmente com os chamados emergentes, como o conjunto da África Austral nucleado pela África do Sul posterior ao Apartheid e com o Mercado Comum do Sul (Mercosul), particularmente com o Brasil. Assim, o Oceano Índico estaria constituindo-se em uma espécie de rota de ligação com o Sul. A cooperação mais estreita com essas regiões, apesar de atualmente possuir um impacto limitado no plano puramente econômico, possui um potencial promissor de médio e longo prazo, além de constitui um elemento estratégico nas disputas entre os pólos desenvolvidos do Hemisfério Norte. Não se pode deixar de considerar que, pelo fato do pólo asiático constituir em linhas gerais uma área em desenvolvimento, existe um amplo espaço para o estabelecimento entre este e os mercados emergentes antes referidos, de uma parceria estratégica capaz de influenciar o futuro perfil da ordem internacional emergente.

\section{A CRISE ASIÁTICA DE 1997, A SEGUNDA TENTATIVA DE CONTENÇÃO}

O contínuo desenvolvimento econômico asiático, contudo, sofreu em 1997 o forte impacto da crise financeira, que atingiu vários países e repercutiu na região como um todo. A chamada crise asiática teve antecedentes no Japão, que desde o final dos anos 1980 conhecia dificuldades econômicas, e buscava cooperar com o continente para compensar seus crescentes problemas com os EUA. Em 1991 estourou a "bolha imobiliária", que produziu igualmente a explosão da "bolha financeira". Para evitar a inflação, o governo bloqueou a oferta de dinheiro, condenando o país à estagnação. Ao mesmo tempo, vários bancos faliam, sem que o Estado pudesse socorrer a todos.

No momento em que a China começou a concretizar seu processo de reunificação (iniciado com a devolução de Hong Kong em 1997) e os Tigres tentavam consolidar seu desenvolvimento em moldes autônomos, prosseguia a estagnação japonesa e, em seguida, ocorreu o terremoto financeiro nos países mais vinculados e dependentes dos Estados Unidos (Tailândia, Indonésia e Coréia do Sul). Essa crise, apesar de haver reduzido inicialmente a produção, afetou especialmente o âmbito financeiro, com a desvalorização das moedas locais, o que permitiu ao capital forâneo adquirir empresas nacionais a um preço reduzido. Além disso, intensificavam-se as pressões pela fragmentação da China (revivendo a questão do Tibete e de Taiwan) e contra a Indonésia, que acabaram derrubando o regime autoritário de Suharto. Mas a China e a Malásia, bem como o Vietnã, resistiram à crise e a Coréia do Sul recuperou-se.

A crise ocorreu em um contexto em que o desenvolvimento da Ásia-Pacífico vinha encaminhando-se para uma interiorização no continente e seu centro, o que é particularmente visível não apenas pela intensificação das relações econômicas entre os próprios países asiáticos. Já a corrida armamentista (particularmente naval) na Ásia Oriental tem sido percebida de maneiras diferentes. Enquanto para analistas ocidentais essa corrida evidencia a ascensão da rivalidade e da desconfiança entre os estados asiáticos, para muitos destes representa implicitamente a capacitação e modernização militar, como forma de dissuadir coletivamente possíveis ingerências extra-regionais contra a sua soberania (conceito hoje desprezado no Ocidente, mas profundamente arraigado na Ásia).

\section{GUERRAAO TERRORISMO, A TERCEIRA TENTATIVA DE CONTENÇÃO}

A Guerra ao Terrorismo, que os Estados Unidos desencadeou após os atentados de 11 de setembro de 2001, inaugurou uma ampla intervenção na Ásia central e ocidental. A implantação americana no Afeganistão e no Iraque, bem como a presença militar parcial no Cáucaso e nas repúblicas ex-soviéticas da Ásia Central, bem como a exploração da crise coreana e da luta contra o terrorismo na linha que vai do sul das Filipinas até o 
Paquistão, evidencia o perfil da política externa do governo Bush para a Ásia. Parece haver a intenção de inserir uma cunha no coração geopolítico da Eurásia, dificultando a integração física da Rússia com a China. Esta manifestou discretamente o que considerou um cerco estratégico por Washington, além da ameaça que paira quanto ao acesso ao petróleo da Ásia central por parte da economia chinesa.

Por meio de guerras teatrais contra os debilitados países do chamado Eixo do Mal, conforme Todd (2003), o que a administração republicana busca é conter a formação de uma constelação de pólos de poder na Eurásia, capazes de contribuir para a formação de um sistema internacional multipolar. O desenvolvimento e a autonomia da Eurásia deixariam a América "marginalizada", uma vez que perderia sua posição de liderança junto à economia e ao sistema de segurança mundial. Daí manter-se uma situação de instabilidade permanente na região. Como os pólos de poder asiático estão reagindo? Com muita cautela. A Coréia do Sul tenta evitar uma escalada, mantendo negociações com o Norte e, juntamente com o Japão e a China, tentando impedir uma ação americana.

A China, por sua vez, teve uma atuação discreta quanto à guerra contra o Iraque, evitando polemizar demasiadamente com os EUA. O intercâmbio econômico com Washington é vantajoso e Pequim necessita manter seu crescimento econômico ao menos por mais uma década. Ao mesmo tempo, o dragão chinês busca cada vez mais associar os vizinhos ao seu processo de desenvolvimento econômico, o que vem fazendo com sucesso, enquanto participa nas iniciativas regionais de cooperação, econômicas, políticas ou de segurança, como no caso da Asean. Assim, a China vai tornando-se o centro de gravidade da Ásia e, discretamente, participando de modo prudente, mas segura, na grande diplomacia mundial. Ela seguramente conformará um pólo de poder com alguns países vizinhos, em um sistema internacional multipolar, regido por uma ONU redimensionada pelo novo equilíbrio de forças que se viria a formar.

\section{O MUNDO EM DESENVOLVIMENTO SE TORNAESTRATÉGICO PARAACHINA: O CASO DA ÁFRICA}

Evitando confrontar os EUA na Ásia central, Pequim buscou áreas não cobertas pelo "lençol curto" da capacidade militar norte-americana. Estreitou a cooperação político-econômica com os vizinhos asiáticos e intensificou o comércio com a América Latina e seus regimes esquerdistas, mas sem confrontar Washington nessa região que é sua área de influência. Ao mesmo tempo, a China aproximou-se do continente africano, tanto por motivos econômicos (mercados e matérias-primas) quanto diplomáticas (combater a presença remanescente de Taiwan). Em novembro de 2006 foi realizada, em Pequim, a terceira Cúpula China-África, com a presença de mais de 40 lideres africanos, ocorrendo o lançamento de uma espécie de Plano Marshall chinês para o continente, por meio de investimentos em infraestrutura e ajuda ao desenvolvimento

O desenvolvimento econômico chinês e o fim da Guerra Fria foram determinantes para as relações entre a China e a África. Até então, a política externa chinesa para o continente negro baseavase na antiga disputa ideológica, primeiramente com os Estados Unidos e as potencias coloniais européias, e, depois, com a União Soviética. Assim, a China buscava parcerias que convergissem com sua posição conjuntural, bem como uma diplomacia de prestígio. Quando o país distanciava-se da URSS, aliava-se com aqueles que fossem contra a infiltração do bloco soviética no continente, como em uma tentativa de polarizar o sistema internacional de uma forma mais intensa. Assim, durante a década de 1980, houve um decréscimo nas relações sino-africanas, pois muitos acreditavam que a China não precisa da África como das potências ocidentais para edificar seu próprio fortalecimento econômico.

Quando o bloco soviético começava a esfacelar-se, ocorreu um episódio bastante importante para os acontecimentos posteriores envolvendo esses atores. Os eventos da Praça da Paz Celestial geraram forte reação da comunidade internacional. A reação por parte de governantes africanos, todavia, foi diferente. Não faltaram líderes que defendessem a atitude do governo chinês. Dessa forma, a China passou a encarar a África de outra forma, visualizando uma possível aliança política que lhe serviria de sustentação, principalmente na ONU. Paralelamente, a China aproveitava a ocasião para minar a presença de Taiwan no continente. Percebeu-se, igualmente, que haveria vantagens econômicas possíveis com os africanos, e a política externa voltou-se mais em direção ao continente. 
Outro ponto comum entre chineses e africanos é o fato de que compartilhavam a visão de que as críticas ocidentais apenas procuravam retardar o desenvolvimento dos países mais pobres. Ambos têm um passado comum de exploração européia, o que os torna desconfiados de eventuais manifestações contrárias às suas políticas domésticas e soberania. Além disso, a possibilidade de crescimento econômico, desvinculado da sujeição a agendas de liberalização política impostas pelos países da Organização para a Cooperação e Desenvolvimento Econômico (OCDE) anima inúmeros governantes africanos.

O continente passou, então, a ser considerado pela política externa chinesa como o maior espaço de aliados no mundo. Por outro lado, os africanos vêem com bons olhos a parceria com a China, sobretudo devido à posição dessa no Conselho de Segurança da ONU. Depois de 1989, a ajuda humanitária e os negócios entre as partes cresceram significantemente. O número de visitas diplomáticas entre chefes de Estado voltou a ter um ritmo ascendente, e foram criadas novas iniciativas para que empresas pudessem deslocarse para o continente. Naturalmente, as empresas estatais foram pioneiras, mas logo seguidas pela iniciativa privada e atores subnacionais chineses.

Vale notar que a China tem, historicamente, relações amigáveis com seus vizinhos. Sempre foi de seu interesse buscar parcerias para evitar confrontos futuros, de modo a forjar um jogo de soma positiva. Por isso, os chineses sempre evitaram a intervenção em assuntos internos de outras nações. Aos africanos, evidentemente, isso era muito favorável, pois os organismos internacionais, tais como o Fundo Monetário Internacional (FMI), sempre condicionam empréstimos a medidas de ajuste econômico restritivo e choques de gestão, além de um elevado grau de liberalização políticoeconômica que comprometiam a governabilidade dos estados africanos.

Os chineses, por outro lado, concedem ajuda sem questionamentos e com poucas exigências. Essas medidas são muito criticadas pelo Ocidente, que detrata a ajuda chinesa a países com histórico de desrespeito aos direitos humanos, os chamados "estados delinqüentes". Essas reclamações são encaradas com ceticismo por parte de africanos e chineses, que entendem que se trata de mais uma tentativa de impedir o desenvolvimento só- cio-econômico de ambos, pois isso dificultaria sua subserviência às potências do Norte.

No decorrer da década de 1990, o acelerado crescimento econômico pelo qual passava a China suplantou a limitada oferta de petróleo que as estatais do país produziam, em comparação com as crescentes necessidades. Além disso, uma grande parcela da população deixou a linha da pobreza, sobretudo aqueles que saíram do campo. Há alguns anos, Angola tornou-se o maior fornecedor do combustível para o país asiático, superando a Arábia Saudita. Além disso, os chineses importam outros minérios e vários produtos alimentícios.

Com base nesses princípios, ocorreu, em 2000, a criação do Fórum de Cooperação China-África, que visa a regulamentar as relações entre as partes, de modo a promover o desenvolvimento mútuo. As reuniões são trienais e seus principais pontos não se limitam ao aumento do comércio, mas também à cooperação científico-tecnológica e à ajuda econômica chinesa, que ocorrem, sobretudo, por meio de investimentos em infraestrutura. Na última reunião do Fórum, em 2009, os chineses prometeram conceder dez bilhões de dólares em empréstimos aos países africanos, além de favorecer a iniciativa privada chinesa a investir mais no continente negro.

Quando os Estados Unidos iniciaram uma grande intervenção na Ásia central e no Oriente Médio, em função da "guerra ao terrorismo", os interesses chineses foram gravemente afetados. Havia projetos de oleodutos e gasodutos em marcha nessas regiões, e a segurança energética foi ameaçada. Para evitar confrontos com Washington, Pequim procurou um espaço onde sua inserção fosse menos onerosa diplomaticamente. Esse espaço era a África e, em menor medida, a América do Sul. Na mesma linha, a crescente necessidade de minerais, alimentos e outras matérias primas, além de áreas para investimento de capitais chineses e mercados para seus produtos, fez que a cooperação sino-africana atingisse um patamar estratégico.

A oferta de prédios públicos (palácios presidenciais, ministérios, hospitais, escolas, centros de convenções e estádios esportivos) entusiasmou os africanos. Os produtos chineses, extremamente baratos, encontraram na África um espaço inesperado, permitindo aos africanos o acesso a um 
consumo antes inimaginado. Mesmo em remotas aldeias africanas há um pequeno comércio chinês do tipo "1,99". Grandes obras de infraestrutura, novas ou reconstruídas após décadas de guerra geram milhões de empregos, embora a China empregue, em muitos casos, sua própria mão de obra e haja algumas tensões localizadas. Projetos de mineração, prospecção de petróleo, exploração de madeira, projetos agrícolas, assistência técnica e vultosos investimentos mudaram o panorama econômico africano.

Mais ainda, os africanos deixaram de solicitar empréstimos ao FMI, passaram a ser mais seletivos com a ajuda ocidental e, sobretudo, a desenvolver uma diplomacia mais assertiva. Se há casos de corrupção, isso também havia com os negócios europeus. $\mathrm{O}$ fornecimento de armamento e o apoio diplomático chinês, sobretudo vetando iniciativas ocidentais no Conselho de Segurança da ONU contra estados africanos, elevaram a autoconfiança do continente, que não se sente mais abandonado. É isso que Bruxelas, Washington e as organizações não-governamentais não conseguem compreender. Para os africanos, trata-se de uma descolonização econômica e de uma nova projeção internacional.

A atuação chinesa suscita reações bastante diversas na comunidade internacional. Os pontos positivos são o crescimento econômico por que os países africanos vêm experimentando e o investimento pesado em infraestrutura, sempre negligenciado pelos europeus. Por outro lado, apesar das críticas, há, globalmente, um equilíbrio comercial entre os estados africanos e a China. Há quem argumente, ainda, que essa relação não passaria de uma espécie de neoimperialismo à chinesa, e que a concessão de empréstimos sem a exigência de garantias político-institucionais favoreceria ditaduras.

Os detratores ignoram, contudo, que a maioria dos africanos exalta a participação chinesa, sempre fazendo questão de diferenciá-la da européia. Essa atuação é bastante coerente com o histórico da política externa chinesa, que prioriza a não intervenção nos assuntos domésticos. Vê-se, portanto, uma nítida intenção de fortalecimento político-econômico por parte dos chineses, que vêem na África uma oportunidade ímpar para expandir negócios, encontrar parceiros diplomáticos e alterar o perfil da ordem mundial, rumo à multipolaridade. Resta, por enquanto, esperar para que os africanos organizem-se melhor para que estabeleçam uma política coerente em relação à China. Até o momento, os chineses sempre tomam a dianteira e regem as negociações, mesmo que elas sejam organizadas bilateralmente.

Assim, a chegada da China à periferia em desenvolvimento, com uma agenda política e econômica abrangente, parece inaugurar um novo estágio na projeção internacional chinesa e no próprio sistema mundial. A China estabeleceu com a África, por exemplo, uma relação que não é meramente conjuntural, mas irreversível. Ainda que sem condições de impor nada aos africanos, et pour cause, Pequim inaugura uma nova etapa na grande política internacional e suplanta a fase em que a Nova China lutava para recuperar sua soberania e desenvolvimento, pois a Novissima Chi$n a$ começa a transformar o próprio sistema mundial.

Paulo G. Fagundes Visentini (paulovi@ufrgs.br) é Doutor em História Econômica pela Universidade de São Paulo (USP) e Professor de Relações Internacionais na Universidade Federal do Rio Grande do Sul (Ufrgs).

\section{REFERÊNCIAS BIBLIOGRÁFICAS}

HALLIDAY, F. 2007. Repensando as Relações Internacionais. Porto Alegre: UFRGS.

HUNTINGTON, S. P. 1997. O choque de civilizações. Rio de Janeiro: Objetiva.

MEDEIROS, C. 1999. China: entre os séculos
XX e XXI. In: FIORI, J. L. (org.). Estados e moedas no desenvolvimento das nações. Petrópolis: Vozes.

TODD, E. 2003. Depois do império. São Paulo: Record. 


\section{THE NEW CHINA AND THE INTERNATIONAL SYSTEM}

\section{Paulo G. Fagundes Visentini}

China has arrived on the periphery of development, bringing with it a wide political and economic agenda. This marks a new phase in China's international projection and in the world system itself. What are the goals of this new New China in terms of international politics? There are many who claim that China entertains ambitions of world dominance, seeking to move into the position the United States has held in terms of planetary leadership. In a manifestation of what comes close to resembling sino-phobia (a new version of the "yellow threat"), there are those who argue that Chinese development seeks to concentrate world wealth, breaking up the economies of other nations of the world. In advancing the hypothesis that Peking has inaugurated a new stage in international politics, substituting the one in which the New China was struggling to regain sovereignty and development, we base our argument on the relationships that China has established with the African 
continent. The new New China, then, has begun to transform the world system itself. In this sense, we argue, China has sought to avoid hegemonies, whether that of the Unitied States or its own. If this were not so, its fate could turn out to be similar to that of Germany's, in the aftermath of two World Wars. Yet such strategies might not be feasible, since China must act today within the context of post-World War diplomatic fluidity and an aging contemporary capitalism whose historic centers are in rapid decline .

KEYWORDS: Chinese Diplomacy; International System; China-Africa Relations. 


\section{LA NOUVELLE CHINE ET LE SYSTÈME INTERNATIONAL}

\section{Paulo G. Fagundes Visentini}

L'arrivée de la Chine à la périphérie en développement, avec un agenda politique et économique varié, inaugure une nouvelle étape dans la projection internationale chinoise et même dans le système mondial. Quels seraient les objectifs de cette Nouvelle Chine par rapport à la politique internationale? Il y a ceux qui identifient dans les initiatives chinoises, des aspirations ambitieuses de domination mondiale, succédant les États Unis autant que pays en tête de la planète. Avec une manifestation qui tend vers la sinophobie (connue avant comme la " peur jaune »), on argumente que son développement souhaite concentrer la richesse mondiale dans ses mains, en brisant l'économie des autres nations. En ayant comme principe les relations établies avec le continent africain, nous soutenons l'hypothèse selon laquelle, Pékin inaugure une nouvelle étape dans la grande politique internationale et supplante la phase où la Nouvelle Chine luttait pour récupérer sa souveraineté et son développement, et ainsi, la Nouvelle Chine commence à transformer le système mondial luimême. Pour cela, nous argumentons que la Chine cherche à éviter l'hégémonie, celle des États Unis, et la sienne aussi. Car dans ce cas, elle pourrait avoir le même sort que l'Allemagne dans les deux guerres mondiales. Ce n'est pas une tâche facile, car la Chine se déplace entre la fluidité diplomatique de la période postérieure à la Guerre Froide, et le vieillisement du capitalisme contemporain dans ses centres historiques.

MOTS-CLÉS: la diplomatie chinoise; le système international; les relations Chine-Afrique. 